\title{
NOTES ON SOME BACTERIAL PARASITES OF THE HUMAN MUCOUS MEMBRANES
}

\author{
Wade W. Olifer and William B. Wherry \\ From the Laboratory of Bacteriology and Hygiene, University of Cincinnati
}

The following observations are offered in the hope that they may be of service to others who may take up the study of the extensive and imperfectly described bacterial flora of the human mucous membranes.

\section{BACTERIUM MELANINOGENICUM (N.SP.)}

The occurrence of black colonies on anaerobic blood-agar cultures from carious teeth, etc., has been noted by several investigators. No one, so far as we are aware, has isolated and described the organism. We have isolated it from the throat, tonsils, infected surgical wound of the abdomen, from urine collected as aseptically as possible from a suspected focal infection of the kidney, and from the feces of a case of chronic dysentery superimposed on an original amebic infection.

Isolation and Biologic Characters.-The bacterium grows readily at $37 \mathrm{C}$. on +1 human blood-agar slants made anaerobic by the pyrogallic acid method. In primary cultures, the colonies become visible within one to two weeks. Pure subcultures yield a confluent, black, dry layer of growth (fig. 1), within which lie the somewhat polymorphous rods, embedded in the masses of pigment. As the growth increases the hemoglobin throughout the agar slant disappears, until finally the medium appears like a slant of plain agar. The growth of the bacterium on infusion agar is greatly facilitated by the presence of hemoglobin, and pigment production is absolutely dependent on it.

In sodium phosphate broth $(+1)$ the organism produces acid from dextrose, levulose, lactose, saccharose, maltose and mannite. Galactose is not attacked. On potato no growth occurs, nor does growth occur on agar or broth made from Liebig's beef extract, with or without dextrose or maltose. In gelatin containing pleuritic fluid there is a dense flocculent growth at $37 \mathrm{C}$., but no liquefaction. On Loeffler's blood serum a fairly luxuriant, white, moist layer of growth develops. Litmus milk is slowly acidified, but not coagulated.

The bacterium occurs as somewhat polymorphous rods, in size about $0.8 \mu \times 1 \mu-3 \mu$ (fig. 2). They lose the stain in Gram's 
method and are nonacid-fast. Motility is absent in both sealed and unsealed preparations.

The rods themselves are unpigmented. The pigment occurs as extracellular, amorphous masses, and apparently is a melanin. The pigment is insoluble in alcohol, ether, chloroform, acetone, carbon-disulphide and carbon-tetra-chloride. It slowly dissolves in sodium hydroxide solution.

\section{B. DUPLEX-NONLIQUEFACIENS IN BRONCHIAL SPUTUM}

This bacterium has been encountered not infrequently in the muco.* purulent sputum of acute and chronic bronchitis. It seemed to be particularly prevalent in Cincinnati in 1915. Often it was present in the bronchial sputum in quite as large numbers as the members of the pneumococcus group (fig. 3). According to Scarlett, ${ }^{1}$ this species sometimes occurring in ulcer of the cornea can easily be distinguished from the diplobacillus of Morax-Axenfeld and that of Petit by means of specific agglutinating serums.

Our cultures corresponded with B. duplex in their cultural characters, except that they failed to liquify blood serum slants. Particularly luxuriant growth was obtained on slants of ascites agar grown at $37 \mathrm{C}$. under partial tension with the hay bacillus. In such cultures, the diplobacillus arrangement was retained (fig. 4).

A whole ascites-agar slant culture was injected into the pleural cavity of a rabbit. When the rabbit was killed and examined a month latter it appeared normal.

\section{M. MINUTISSIMUS (N.SP.)}

This organism, apparently an obligate anaerobe, was isolated from the mixed flora in the aphthous ulcers of the gingival and buccal mucosa of a case of postpoliomyelitic paralysis. It appears as spherical, nonmotile cocci and diplococci less than $0.5 \mu$ in diameter (fig. 5, in which they are photographed along with $\mathrm{S}$. aureus). The coccus stains readily with the ordinary aniline dyes but loses the stain in Gram's method.

When grown anaerobically by the pyrogallic acid method on sodium phosphate nutrient agar containing pleuritic fluid, discrete colonies are formed. They are opaque, white and attain a diameter of $1 \mathrm{~mm}$. When grown anaerobically by the pyrogallic acid method on sugar-free

1 Ann d'Oculistique, 1916, 153, 485. 
phosphate agar ( +0.8 to phenolphthalein) containing $1 \%$ of dextrose, levulose, galactose, lactose, saccharose, maltose, mannite and pleuritic fluid, the growth was more luxuriant than on plain pleuritic fluid agar, and bubbles of gas appeared in the water of syneresis. If litmus was present in the above sugar mediums, after 4 days' growth at $37 \mathrm{C}$, the litmus was reduced. On opening the tubes, they turned a deep blue color. In sugar-free sodium phosphate broth a large bubble of gas was produced which was not absorbed by sodium hydroxide and was noninflammable. An attempt to adapt the organism to aerobic growth failed.

A rabbit was inoculated intravenously and a guinea-pig and white mouse intraperitoneally, each with a whole slant of the culture. None of the animals were infected.

\section{M. RENIFORMIS (DIPLOCOCCUS RENIFORMIS, COTTET, 1900)}

This coccus was isolated in ascites-agar cultures, made anaerobic by the pyrogallic acid method, from the vaginal pus of a case of vulvovaginitis in a child. Numerous gonococci were present in the pus, as revealed by direct smears and cultures incubated at partial tension.

M. reniformis tends to occur as bean-shaped diplococci slightly smaller than the gonococcus. In cultures, it retains a fairly uniform size, without the production of the swollen involution forms which so soon appear in cultures of the gonococcus. It loses the stain in Gram's method, but is somewhat more slowly decolorized than the gonococcus.

The growth of this strictly adapted anaerobe ceased at $6 \mathrm{~mm}$. from the surface of a stab culture in ascitic agar. It died on exposure to the air. Growth failed to occur on Loeffler's blood serum, plain nutrient agar or broth, milk and potato. During 8 days' incubation at 37 C. it did not ferment dextrose, levulose, galactose, saccharose, lactose, maltose and mannite. After 8 days' incubation at $37 \mathrm{C}$. in indolfree broth containing sodium phosphate and ascitic fluid, a marked reaction for indol was obtained with $\mathrm{H}_{2} \mathrm{SO}_{4}$ and $\mathrm{K} \mathrm{NO}_{2}$.

We presume that our culture is probably identical with that of Cottet, ${ }^{2}$ although he merely records the morphology, reaction to Gram's stain, strict anaerobiosis and the character of its growth on agar and gelatin. He found that the organism produced a localized abscess when inoculated into the skin of a guinea-pig and smears made from the pus resemble those from a case of gonorrhea rather closely. Cottet called attention to the danger of mistaking it for the gonococcus in smears and

\footnotetext{
2 Compt. rend. Soc. de biol, 1900, 52, p. 421.
} 
to its probable pathogenicity. It was encountered by him in four cases of abscess of the urinary tract, in the pus from a case of pyonephrosis, and in almost pure culture in the urine of a case of cystitis. He states that Veillon and J. Halle, according to a verbal communication, found it in mixed culture in a case of gangrenous inflammation of the vestibule of the vulva of a little girl. 


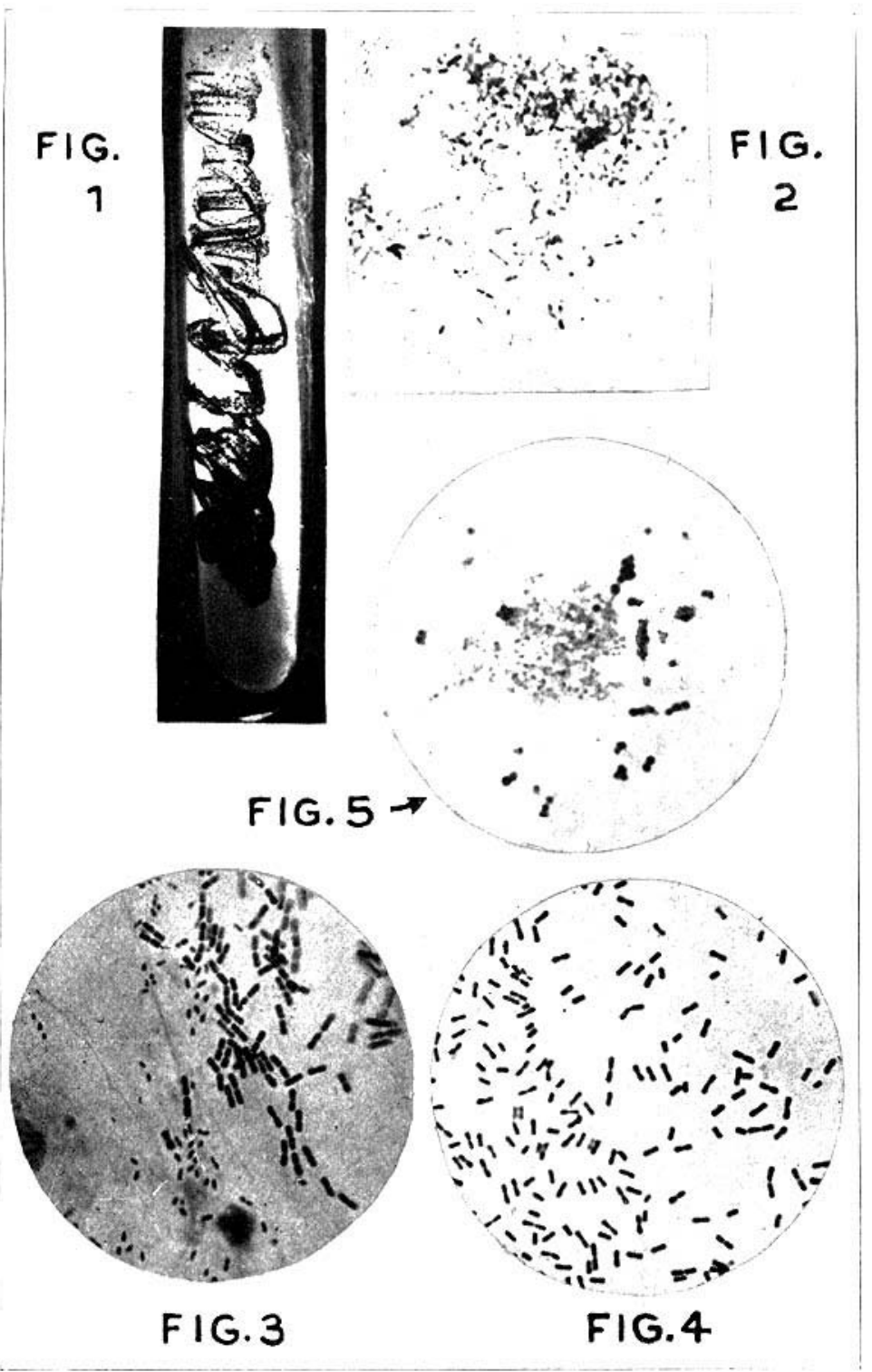

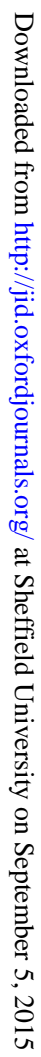

Fig. 1.-Bacterium melaninogenicum (N, Sp.) anaerolic bloot-agar slant culture.

Fig. 2.- Bacterium melaninogenicum from an anaerobic blood-agar culture showing the rods lying among pigment granules; $X$ about 1,000 .

Fig. 3.--B. duplex-1n, nliquefaciens. Smenr from bronchial sputum stained with gramsafranin; $X$ about 1,000 .

Fig. 4.-B. duplex-poniquefaciene from partial tension ascites-agar culture; $X$ about 1,000

Fig. 5.-M. n!: coccus aurens and stained by gram-safranin; $x$ alout 1,000 . 